Published in final edited form as:

Int J Radiat Oncol Biol Phys. 2010 March 1; 76(3 Suppl): S116-S122. doi:10.1016/j.ijrobp.2009.02.090.

\title{
Radiation Dose-Volume Effects Of The Urinary Bladder
}

\author{
Akila N. Viswanathan, M.D., M.P.H. ${ }^{*}$ Ellen D. Yorke, Ph.D. ${ }^{\dagger}$, Lawrence B. Marks, M.D. ${ }^{\ddagger}$ \\ Patricia J. Eifel, M.D.§, and William U. Shipley, M.D.ף \\ "Department of Radiation Oncology, Brigham and Women's Hospital/Dana-Farber Cancer \\ Institute and Harvard Medical School, Boston, MA \\ tDepartment of Radiation Oncology, Memorial Sloan-Kettering Cancer Center, New York, NY \\ ‡Department of Radiation Oncology, University of North Carolina, Chapel Hill, NC \\ §Department of Radiation Oncology, M. D. Anderson Cancer Center, Houston, TX \\ IDepartment of Radiation Oncology, Massachusetts General Hospital and Harvard Medical \\ School, Boston, MA
}

\begin{abstract}
An in-depth overview of the normal-tissue radiation tolerance of the urinary bladder is presented. The most informative studies consider whole-organ irradiation. The data on partial-organ/ nonuniform irradiation are suspect because the bladder motion is not accounted for, and many studies lack long enough follow-up data. Future studies are needed.
\end{abstract}

\section{Clinical Significance}

Radiotherapy (RT) with or without chemotherapy for pelvic malignancies may result in genitourinary (GU) complications. Overall, severe late effects occur in $₫ 0 \%$ of patients with prostate, bladder, or cervical cancer (1). However, given a possible latency period of several decades between treatment and the clinical manifestation of sequelae $(2,3)$, reports may have underestimated the late GU toxicity rates. The reported rates of acute side effects might be more accurate.

\section{Endpoints}

Many endpoints may be used to score bladder injury. In the present report, we focus on clinical symptoms. The symptoms attributed to RT-related injury can also occur as a consequence of other medical co-morbidities, such as infection or aging, particularly for incontinence. The toxicity profile will depend on the treatment regimen of RT with or without surgery or chemotherapy, and the origin, extent, and location of cancer. When discussing bladder toxicities in relation to dose and/or volume, a significant heterogeneity of dose can exist, depending on whether the patient has undergone brachytherapy, teletherapy, or both, and on bladder motion.

\footnotetext{
Copyright @ 2010 Elsevier Inc.

Reprint requests to: Akila N. Viswanathan, M.D., M.P.H., Department of Radiation Oncology, Brigham and Women's Hospital/DanaFarber Cancer Institute, Harvard Medical School, 75 Francis St., L2, Boston, MA 02115. Tel: (617) 732-6331; Fax: (617) 278-6988; aviswanathan@lroc.harvard.edu.

Conflict of interest: none

Bladder dose, toxicity.
} 
Acute side effects that occur during RT usually resolve within a few months. Long-term symptoms attributable to global injury include dysuria, frequency, urgency, contracture, spasm, reduced flow, and incontinence. In contrast, symptoms thought to arise from focal injury include hematuria, fistula, obstruction, ulceration, and necrosis. The grading of toxicities according to treatment given is subjective. One physician might prescribe an intervention sooner than another, leading to a relative "upgrading." Furthermore, symptoms attributable to the bladder might be urethral in origin. Several scoring systems have been proposed to standardize the reporting of bladder toxicity, each with a slightly different approach. Some systems have separately considered objective vs. subjective endpoints (e.g., Late Effects of Normal Tissues-Subjective, Objective, Management and Analytic system [LENT-SOMA]), and others have not differentiated between acute and late effects (e.g., Common Terminology Criteria for Adverse Events [CTCAE]) or have ambiguities (e.g., "spontaneous, pads indicated" is considered Grade 2 incontinence using the CTCAE). Interstudy comparisons are challenging, because the scoring system used was not always clearly stated. Furthermore, crude, rather than actuarial, rates have often been reported. In general, patient-reported data have been shown to be superior to physician-reported data, although the collection is more complex (4).

\section{Challenges Defining Volumes}

The bladder is a highly distensible organ. Its volume continuously changes with filling, and the post-void residual volume can vary. Furthermore, the bladder can move with positioning, respiration, or bowel filling. Therefore, we have referred to a dose-volume histogram (DVH) of the bladder obtained from a single planning computed tomography (CT) image as a "SimDVH" to emphasize that this image is unlikely to represent the true dose distribution delivered to the bladder during the treatment course. The bladder trigone, which, functionally, can be more important than the bladder dome, can be difficult to identify on CT. Some reports have defined the bladder to include the entire organ (with urine), and others have used the wall alone (excluding the urine). SimDVH-based and SimDosesurface-histogram-derived metrics have a high degree of correlation (5), and future comparisons of these with regard to late toxicity will provide useful information.

Theoretically, if the patient is treated with a constant bladder volume, the initial CT scan (and associated SimDVH) would indicate the region receiving dose. However, many patients cannot maintain a consistent bladder volume during the treatment course, and have variable emptying and constant filling. Several studies have noted the nonstatic nature of the bladder and reported wall and/or tumor movement of approximately $1-4 \mathrm{~cm}$ and volume variations of $\$ 44 \%$, using repeated CT scans during therapy (6-8). Determining a true bladder DVH has not been feasible.

\section{Review Of Dose-Volume Data}

To date, no studies have comprehensively reported the true three-dimensional (3D) bladder dosimetry in relation to toxicities. A single 3D image set (SimDVH) is of questionable validity. Data for whole-bladder RT vs. partial-bladder doses are discussed by cancer type.

\section{Bladder cancer}

Table 1 lists selected series of patients treated with external-beam RT (EBRT) for bladder cancer, often in conjunction with transurethral resection of the bladder tumor (TURBT) and/ or chemotherapy (9-19). Studies published before 1995 have been previously reviewed (1). Figure 1 summarizes selected studies from that 1995 publication, as well as more recent studies in which the whole bladder was treated with photons no more than once daily and the corresponding Grade 3 or greater late toxicity rates were reported $(9,11-15,20-26)$. 
Several different fractionation schedules were used; therefore, we plotted the toxicity rate against the normalized total dose in 2-Gy fractions calculated using the linear-quadratic model with an $a / \beta$ of $6 \mathrm{~Gy}$ for consistency with the 1995 study by Marks et al. (1), although others have reported using an $\alpha / \beta$ of 3 Gy. Two studies included in Fig. 1 reported late toxicity rates of $225 \%$ with hypofractionated treatment schedules $(20,21)$, as did one study of partial-bladder RT that used $2 \mathrm{~Gy} /$ fraction to a total of $62 \mathrm{~Gy}$ (15). Because these studies used RT portals that encompassed the entire bladder with a margin large enough to account for motion, we anticipated that the whole bladder received the prescription dose.

Nonetheless, a large variation was found in the reported severe late bladder toxicity rates, indicating that an increasing dose does not account for all toxicity. Variations in reporting, treatment received (with or without surgery and chemotherapy), radiation dose range within a single study, and the modest number of patients in some studies have confounded the interpretation.

For partial-bladder RT, care must be taken to ensure that the target volume is adequately covered. Several fractionation patterns have been reported; one common regimen has been whole-bladder RT to 52.5-55 Gy in 1.5-1.8-Gy fractions, followed by a partial-bladder boost of 12-15 Gy using 1.5-1.8 Gy/fraction, resulting in a cumulative tumor dose of 64-65 Gy (27). The serious late complication rates were $<25 \%$ for most of the two-phase studies listed in Table 1(15-19), suggesting advantages for a boost strategy. The most recent update of the Radiation Therapy Oncology Group bladder cancer trials of TURBT, chemotherapy, and RT reported a late Grade 3 or greater GU toxicity rate of $6 \%$ (19). Although studies have suggested that larger fraction size might increase the incidence of late complications $(12,28)$, similar to accelerated fractionation (10), the currently available data are inadequate to determine late bladder tolerance quantitatively for the range of doses encountered with EBRT for bladder cancer.

\section{Prostate cancer}

The bladder neck and prostatic urethra are adjacent to, or within, the treated volume for prostate cancer. The distinction between bladder and urethral symptoms cannot be reliably made by the physician. The low rate of GU toxicity in post-prostatectomy series $(29,30)$ suggests that the prostate and prostatic urethra, rather than the bladder, might cause most GU symptoms. In the era before 3D imaging, a whole-pelvic approach, followed by a boost to the prostate with a margin, resulted in the inferior part of the bladder receiving the full dose. During the past decade, dose escalation and the use of conformal techniques, including intensity-modulated RT (IMRT), have delivered high doses ( $\geq 70 \mathrm{~Gy}$ ) to the prostate and, hence, to the inferior portion of the bladder. With these techniques, the superior part of the bladder is either outside the field for the entire treatment or receives approximately the full dose from the first treatment phase but is outside the cone-down field. This is in contrast to the trigone region, which lies immediately adjacent to the prostate and might receive the full prescription dose.

The question of dose response for late GU toxicity in prostate-cancer treatment has not been resolved. The vast majority of studies found no dose-volume relationship with regard to GU toxicity. A few studies have indicated an association between the prostate dose and either acute or chronic GU toxicity might exist. Dose-volume relationship studies have been limited given the aforementioned constraints on localization of the bladder during treatment, as well as the duration of follow-up necessary to determine chronic toxicity. In a randomized multi-institutional trial of 669 prostate-cancer patients treated with 3D conformal RT, no significant difference in late GU toxicity was noted between the 68-Gy and 78-Gy treatment arms (31). With a median of 7 years of follow-up, the cumulative Grade 2 or greater toxicity rates were $40 \%$ in the high-dose arm and $41 \%$ in the low-dose arm, and the cumulative Grade 3 or greater toxicity rates were $13 \%$ and $12 \%$, respectively. However, an overall dose 
response for Grade 2 or greater GU toxicity was noted in the most recent report of a singleinstitution study of 1,571 patients by Zelef-sky et al. (32). They reported a cumulative $20 \%$ incidence at 10 years after 81 Gy IMRT to the prostate compared with $12 \%$ for non-IMRT patients treated to lower doses (32). However, in the entire cohort, only 3\% developed Grade $3 \mathrm{GU}$ toxicity, and no Grade $4 \mathrm{GU}$ toxicity was noted. The median interval to the development of symptoms was 30 months, and $<1 \%$ developed late GU toxicity after 10 years. The investigators did not attempt to report the DVH values (32).

\section{Gynecologic cancer}

Historical data have indicated that locally advanced cervical cancer treated with high doses (>60 Gy) of EBRT alone results in a high incidence of late GU toxicities and a poor outcome (33). Therefore, a combination of EBRT and brachytherapy is used. The dose to the entire bladder with EBRT typically ranges from 40 to $50 \mathrm{~Gy}$, and the total dose with brachytherapy to the region closest to the implant approximates 70-90 Gy and can reach $>100 \mathrm{~Gy}$. However, these regions likely vary between fractions, resulting in an unknown true maximum dose for most patients. The International Commission on Radiation Units Report 38 system assigns a bladder dose point; however, this point is not representative of the CT-based (34-38)or ultrasound-based (39) volumetric dose maximum and surface area of normal tissue irradiated.

Contouring the bladder with a Foley catheter in place during each fraction of brachytherapy more accurately determines the doses received by the bladder. With a median follow-up of 39 months, the mean D2cc of the bladder for 141 patients with locally advanced cervical cancer treated with tandem and ring brachytherapy was $95.3 \pm 21 \mathrm{~Gy}(\alpha / \beta=3) ; 3$ patients experienced Grade 3 or 4 late bladder toxicity, resulting in a 3-year actuarial rate of $4 \%$. Of those treated with a bladder dose to D2cc of $<95 \mathrm{~Gy}, 13 \%$ (11 of 87) developed Grade 1-4 late toxicity compared with $17 \%$ (9 of 54) if that dose was $>95 \mathrm{~Gy}$. These differences were not significant, indicating that the focal dose threshold is not clear from the available data (40-42). No Grade 3 or 4 GU toxicities were reported for 10 patients treated with magnetic resonance imaging-guided interstitial gynecologic brachytherapy with a median D2cc to the bladder of 69 Gy after a 2-year median follow-up $(43,44)$. Longer follow-up of these studies is needed.

\section{Factors Affecting Risk}

\section{Co-morbidities}

Among patients undergoing RT for prostate cancer, an increased risk of late GU toxicity has been seen for patients with pre-RT GU morbidity (45-48) and/or acute GU toxicity. After EBRT, an increased rate of Grade 2 or greater GU toxicity has been seen with increasing age and the use of hormones. In cervical cancer, the 10-year bladder complication rate in a series from the M.D. Anderson Cancer Center was 3\%. On multivariate analysis, a central pelvic dose of EBRT >50 Gy (hazard ratio [HR], 3.34; $p=.002$ ), black race (HR, 1.89; $p=.003$ ), smoking history (HR, $1.81 ; p=.006)$, and body mass index $>30 \mathrm{~kg} / \mathrm{m}^{2}(\mathrm{HR}, 1.55 ; p=.05$ ) were significantly associated with bladder complications (49). Age, diabetes, hypertension, or a history of pelvic inflammatory disease were not significantly related to bladder toxicity (49). From the experience of the senior investigators of the present report, patients taking anticoagulation medications might develop hematuria.

\section{Surgery}

TURBP, prostatectomy, hysterectomy, biopsy or any kind of procedure before RT may potentially increase morbidity. The site of TURBT might heal slowly. Hysterectomy or prostatectomy can denervate the bladder, which causes urinary hesitancy or retention, 
resulting in overflow incontinence. Approximately 5\% of patients who undergo radical hysterectomy require chronic suprapubic catheterization; 38-50\% develop detrusor instability, impairment of bladder sensation, alteration in bladder compliance or capacity, or a reduction in the maximal urethral pressure $(50,51)$. In one study (52), transurethral prostate resection (TURP) before definitive RT resulted in incontinence in 5\% of patients compared with $1 \%$ who had not undergone TURP. After EBRT for prostate cancer, the rate of urethral stricture has been reported to range from $2 \%$ to $5 \%$ in patients without previous TURP vs. $6-16 \%$ in patients with previous TURP (1).

\section{Chemotherapy}

Changes in bladder function can occur with chemotherapy alone or with concurrent chemoradiotherapy. Cytoxan is independently associated with chronic hemorrhagic cystitis, incontinence, contractions, vesicoureteral reflux, and urothelial malignancies (53). In one study with 8 years of follow-up of cervical-cancer patients treated with chemoradiotherapy, $3 \%$ developed late bladder side effects (54). During the past one to two decades, selective bladder-preserving approaches for patients with muscle-invasive bladder cancer have included EBRT with concurrent cisplatin-containing chemotherapy. Tumor doses of 64-65 Gy have been well tolerated (19). Chemotherapy administered concurrently with RT can sensitize the normal tissue, although this has not been shown to increase the risk of longterm bladder complications in patients with cervical cancer or bladder cancer.

\section{Fractionation}

Some evidence has supported the association of a high dose per fraction with a greater complication rate (1). Prostate-cancer patients treated with $5.17 \mathrm{~Gy} /$ fraction twice a week through anteroposterior/posteroanterior fields for 9 weeks with a 3-week break mid-way through therapy had a 19\% rate of serious bladder injury (55). These included both global (cystitis and contracture) and focal (fistula) injury. Treatment timing could also be a factor. One study of bladder cancer reported a $32 \%$ risk of severe bladder injury with a split-course technique of $40 \mathrm{~Gy}$ to a large volume of the bladder (whole-pelvic fields), followed by 20 Gy (to a small portion of the bladder) at $2 \mathrm{~Gy} /$ fraction using two-dimensional simulation, with three fractions daily and an inter-fraction interval of $4 \mathrm{~h}$ (56). A series using wholebladder RT for bladder cancer found that 66 Gy delivered within 5 weeks with 2 Gy/fraction twice daily for the last 8 days, with at least a 6-h interval between fractions, resulted in no Grade 3 or greater late GU toxicity at 3 years (10). However, twice-daily treatment for the final 13 days (within 4 weeks total) significantly increased the 3 -year actuarial GU toxicity rate to $31 \%(p=.04)(10)$. In contrast, a randomized trial of 229 patients with muscleinvasive bladder tumors treated without chemotherapy compared $60.8 \mathrm{~Gy}$ in 32 fractions twice daily vs. daily RT to $64 \mathrm{~Gy}$. There was no significant difference between accelerated versus conventional fractionation in acute Grade 2 or 3 bladder toxicity (34\% vs. 36\%) or late chronic hematuria ( $25 \%$ vs. $14 \%)$, increased frequence of micturition (60\% vs. $66 \%$ ) or ureteric stenosis (11\% vs. $9 \%$ ) (57).

\section{6/7. Mathematical/Biologic Models and Special Situations}

Currently, no quantitative models are available that satisfactorily describe the observed serious late bladder toxicity after EBRT, given the lack of a clear dose response for wholebladder RT and overall bladder variability. Given the marked uncertainty of the 3D data on which previously described models were based, we do not recommend that any of the previously described model coefficients be used to predict the outcome. Furthermore, whether different parameter sets might be necessary to describe complications in the setting of RT for prostate, bladder, or gynecologic cancer or in subpopulations of patients with various co-morbidities is not known. 


\section{Recommended Dose-Volume Limits}

Although constraints have been used by some centers, the values of the set constraints have often not been based on preceding data nor on localization of the bladder during fractionated therapy. Unless treatment is to the whole pelvis, a bladder volume determined from a static simulation CT scan will not represent the treated portion of the bladder during a severalweek course of therapy. In the absence of any reliable data, clinicians might consider the dose limits listed in the conventional fractionation arm of the Radiation Therapy Oncology Group (RTOG) 0415 study of prostate cancer, which included a solid bladder constraint of no more than $15 \%$ of the volume to receive a dose $>80 \mathrm{~Gy}$, no more than $25 \%$ of the volume to receive a dose $>75 \mathrm{~Gy}$, no more than $35 \%$ of the volume to receive a dose $>70 \mathrm{~Gy}$, and no more than $50 \%$ of the volume to receive a dose $>65 \mathrm{~Gy}$.

\section{Bladder cancer}

The published reports have not provided robust data on which to base strict dose-volume guidelines. Nevertheless, the published data have suggested that restricting whole-bladder or partial-bladder doses to 64-65 Gy in 36 daily fractions or in 40-42 twice-daily fractions produces a level of late bladder complications equivalent to Radiation Therapy Oncology Group Grade 3 toxicity in $\$ 6 \%$ (19).

\section{Prostate cancer}

The dose distributions for conventional four- and six-field 3D conformal RT to the prostate and seminal vesicles, with an approximately $1-\mathrm{cm}$ margin, limit the volume of bladder receiving the prescription dose. The resultant in-target dose distribution will be relatively uniform, with high regions of dose within the bladder unlikely. For IMRT, physicists at several centers use optimization to constrain the high-dose regions. Several different constraints have been reported, although none have been determined from long-term toxicity data, and all used the SimDVH. Increasingly, many centers use daily image guidance with ultrasound or radiographic imaging of implanted markers for prostate localization. In the future, imaging will allow clinicians to decrease the prescribed margin and might improve our knowledge of the bladder location and delivered dose. Selected centers queried for the present review do not apply bladder constraints when performing prostate brachytherapy.

\section{Gynecologic cancer}

The external-beam component of gynecologic therapy has been limited to 40-50 Gy and rarely results in severe long-term sequelae. However, the addition of brachytherapy increases this dose. In cervical-cancer brachytherapy, an upper dose limit for brachytherapy has not yet been clearly defined (42).

\section{Future Toxicity Studies}

The upper limit of bladder dose tolerance is not known. Future studies detailing the dosevolume data, accounting for organ motion and distension, and having long-term clinical follow-up data are needed. In addition, reports in the future should attempt to address some of the issues listed below.

The use of 3D imaging during conformal RT will facilitate studies that relate the actual dose-volume parameters to the clinical outcomes.

An improved understanding of the physiology of bladder distention might allow construction of deformable models that could facilitate estimates of bladder dose distribution according to the bladder volume and surface area. Statistical methods might also be useful to 
understand the likely degree of bladder motion during a course of RT and to better estimate the delivered 3D doses.

All regions of the bladder might not be equally important for different functions. Studies that estimate the physiologic effect of doses to different regions of the bladder could be helpful.

Statistical approaches such as Cox regression proportional hazard models should be used to adjust for the potential confounding effects of medical co-morbidities and other treatments. Patients with recurrent disease should not be included in such studies because the symptoms from recurrence and repeated treatment could be confounding.

Better determination of the linear-quadratic model parameters describing bladder injury is needed. The radiobiologic determinants of the $a / \beta$ and the biologic model used to calculate a normalized total dose in 2-Gy fractions (EQD2) for high-dose-rate brachytherapy should be analyzed to determine whether they are valid for the high doses administered during cervical-cancer treatment. An increased understanding of the applicability of the model to bladder injury, especially in the setting of brachytherapy, is needed.

Patient-based, rather than physician-derived, toxicity scoring must be reported to better reflect the true symptomatic incidence of bladder injury.

\section{Toxicity Scoring}

Both physician- and patient-generated reports are important to assess toxicities. Symptoms can be graded by patient report, including statements ranging from "not a problem" to "a big problem." Symptoms such as incontinence, hematuria, pads used daily, nocturia, dysuria, frequency, and retention can be assessed with more validity using patient-assessment tools rather than physician-assessment tools, including those that rely on medications prescribed. Given the multiple endpoints that can be used to score toxicity, and to avoid ambiguity, we recommend that objective, quantitative, scoring systems that explicitly consider multiple patient- and physician-based endpoints be used, such as the LENT-SOMA system.

\section{Acknowledgments}

Thank you to Barbara Silver and Christian Kirisits, ScD for reading the manuscript.

\section{References}

1. Marks LB, Carroll PR, Dugan TC, et al. The response of the urinary bladder, urethra, and ureter to radiation and chemotherapy. Int J Radiat Oncol Biol Phys. 1995; 31:1257-1280. [PubMed: 7713787]

2. Eifel PJ, Levenback C, Wharton JT, et al. Time course and incidence of late complications in patients treated with radiation therapy for FIGO stage IB carcinoma of the uterine cervix. Int $\mathbf{J}$ Radiat Oncol Biol Phys. 1995; 32:1289-1300. [PubMed: 7635768]

3. Gardner BG, Zietman AL, Shipley WU, et al. Late normal tissue sequelae in the second decade after high dose radiation therapy with combined photons and conformal protons for locally advanced prostate cancer. J Urol. 2002; 167:123-126. [PubMed: 11743288]

4. Talcott JA, Rieker P, Clark JA, et al. Patient-reported symptoms after primary therapy for early prostate cancer: Results of a prospective cohort study. J Clin Oncol. 1998; 16:275-283. [PubMed: 9440753]

5. Xiong L, Viswanathan A, Stewart AJ, et al. Deformable structure registration of bladder through surface mapping. Med Phys. 2006; 33:1848-1856. [PubMed: 16872092]

6. Hellebust TP, Dale E, Skjonsberg A, et al. Interfraction variations in rectum and bladder volumes and dose distributions during high dose rate brachytherapy treatment of the uterine cervix 
investigated by repetitive CT-examinations. Radiother Oncol. 2001; 60:273-280. [PubMed: 11514007]

7. Muren LP, Smaaland R, Dahl O. Organ motion, set-up variation and treatment margins in radical radiotherapy of urinary bladder cancer. Radiother Oncol. 2003; 69:291-304. [PubMed: 14644489]

8. Turner SL, Swindell R, Bowl N, et al. Bladder movement during radiation therapy for bladder cancer: Implications for treatment planning. Int J Radiat Oncol Biol Phys. 1997; 39:355-360. [PubMed: 9308939]

9. Duncan W, Quilty PM. The results of a series of 963 patients with transitional cell carcinoma of the urinary bladder primarily treated by radical megavoltage X-ray therapy. Radiother Oncol. 1986; 7:299-310. [PubMed: 3101140]

10. Moonen L, van der Voet H, Horenblas S, et al. A feasibility study of accelerated fractionation in radiotherapy of carcinoma of the urinary bladder. Int J Radiat Oncol Biol Phys. 1997; 37:537-542. [PubMed: 9112450]

11. Rodel C, Grabenbauer GG, Kuhn R, et al. Combined-modality treatment and selective organ preservation in invasive bladder cancer: Long-term results. J Clin Oncol. 2002; 20:3061-3071. [PubMed: 12118019]

12. Scholten AN, Leer JW, Collins CD, et al. Hypofractionated radiotherapy for invasive bladder cancer. Radiother Oncol. 1997; 43:163-169. [PubMed: 9192962]

13. Mameghan H, Fisher RJ, Watt WH, et al. The management of invasive transitional cell carcinoma of the bladder: Results of definitive and preoperative radiation therapy in 390 patients treated at the Prince of Wales Hospital, Sydney, Australia. Cancer. 1992; 69:2771-2778. [PubMed: 1571908]

14. Perdona S, Autorino R, Damiano R, et al. Bladder-sparing, combined-modality approach for muscle-invasive bladder cancer: A multi-institutional, long-term experience. Cancer. 2008; 112:75-83. [PubMed: 18008364]

15. Mangar SA, Foo K, Norman A, et al. Evaluating the effect of reducing the high-dose volume on the toxicity of radiotherapy in the treatment of bladder cancer. Clin Oncol (R Coll Radiol). 2006; 18:466-473. [PubMed: 16909970]

16. Cowan RA, McBain CA, Ryder WD, et al. Radiotherapy for muscle-invasive carcinoma of the bladder: Results of a randomized trial comparing conventional whole bladder with dose-escalated partial bladder radiotherapy. Int J Radiat Oncol Biol Phys. 2004; 59:197-207. [PubMed: 15093917]

17. Yavuz AA, Yavuz MN, Ozgur GK, et al. Accelerated superfractionated radiotherapy with concomitant boost for invasive bladder cancer. Int J Radiat Oncol Biol Phys. 2003; 56:734-745. [PubMed: 12788179]

18. Pos FJ, van Tienhoven G, Hulshof MC, et al. Concomitant boost radiotherapy for muscle invasive bladder cancer. Radio-ther Oncol. 2003; 68:75-80.

19. Shipley, WU.; Bae, K.; Efstathiou, JA., et al. Late pelvic toxicity following bladder-sparing therapy in patients with invasive bladder cancer: Analysis of RTOG 89-03, 95-06, 97-06, 99-06. Int J Radiat Oncol Biol Phys; Proceedings of the American Society for Therapeutic Radiology and Oncology 49th Annual Meeting; Los Angeles, CA; 2007. p. S8

20. Quilty PM, Duncan W. Primary radical radiotherapy for T3 transitional cell cancer of the bladder: An analysis of survival and control. Int J Radiat Oncol Biol Phys. 1986; 12:853-860. [PubMed: 2424878]

21. Duncan W, Williams JR, Kerr GR, et al. An analysis of the radiation related morbidity observed in a randomized trial of neutron therapy for bladder cancer. Int J Radiat Oncol Biol Phys. 1986; 12:2085-2092. [PubMed: 3539897]

22. Yu WS, Sagerman RH, Chung CT, et al. Bladder carcinoma: Experience with radical and preoperative radiotherapy in 421 patients. Cancer. 1985; 56:1293-1299. [PubMed: 3928127]

23. Corcoran MO, Thomas DM, Lim A, et al. Invasive bladder cancer treated by radical external radiotherapy. Br J Urol. 1985; 57:40-42. [PubMed: 3971103]

24. Marcial VA, Amato DA, Brady LW, et al. Split-course radiotherapy of carcinoma of the urinary bladder stages C and D1: A Radiation Therapy Oncology Group study. Am J Clin Oncol. 1985; 8:185-199. [PubMed: 4050737] 
25. Pointon RS, Read G, Greene D. A randomised comparison of photons and $15 \mathrm{MeV}$ neutrons for the treatment of carcinoma of the bladder. Br J Radiol. 1985; 58:219-224. [PubMed: 3933604]

26. Goodman GB, Hislop TG, Elwood JM, et al. Conservation of bladder function in patients with invasive bladder cancer treated by definitive irradiation and selective cystectomy. Int J Radiat Oncol Biol Phys. 1981; 7:569-573. [PubMed: 7052940]

27. Shipley WU, Kaufman DS, Zehr E, et al. Selective bladder preservation by combined modality protocol treatment: Long-term outcomes of 190 patients with invasive bladder cancer. Urology. 2002; 60:62-68. [PubMed: 12100923]

28. Quilty PM, Duncan W, Kerr GR. Results of a randomised study to evaluate influence of dose on morbidity in radiotherapy for bladder cancer. Clin Radiol. 1985; 36:615-618. [PubMed: 4064546]

29. Zelefsky MJ, Aschkenasy E, Kelsen S, et al. Tolerance and early outcome results of postprostatectomy three-dimensional conformal radiotherapy. Int J Radiat Oncol Biol Phys. 1997; 39:327-333. [PubMed: 9308935]

30. Feng M, Hanlon AL, Pisansky TM, et al. Predictive factors for late genitourinary and gastrointestinal toxicity in patients with prostate cancer treated with adjuvant or salvage radiotherapy. Int J Radiat Oncol Biol Phys. 2007; 68:1417-1423. [PubMed: 17418972]

31. Al-Mamgani A, van Putten WL, Heemsbergen WD, et al. Update of Dutch multicenter doseescalation trial of radiotherapy for localized prostate cancer. Int J Radiat Oncol Biol Phys. 2008; 71:1028-1033. [PubMed: 18280056]

32. Zelefsky MJ, Levin EJ, Hunt M, et al. Incidence of late rectal and urinary toxicities after threedimensional conformal radiotherapy and intensity-modulated radiotherapy for localized prostate cancer. Int J Radiat Oncol Biol Phys. 2008; 70:1124-1129. [PubMed: 18313526]

33. Logsdon MD, Eifel PJ. FIGO IIIB squamous cell carcinoma of the cervix: An analysis of prognostic factors emphasizing the balance between external beam and intracavitary radiation therapy. Int J Radiat Oncol Biol Phys. 1999; 43:763-775. [PubMed: 10098431]

34. Fellner C, Potter R, Knocke TH, et al. Comparison of radiography- and computed tomographybased treatment planning in cervix cancer in brachytherapy with specific attention to some quality assurance aspects. Radiother Oncol. 2001; 58:53-62. [PubMed: 11165682]

35. Pelloski CE, Palmer M, Chronowski GM, et al. Comparison between CT-based volumetric calculations and ICRU reference-point estimates of radiation doses delivered to bladder and rectum during intracavitary radiotherapy for cervical cancer. Int J Radiat Oncol Biol Phys. 2005; 62:131-137. [PubMed: 15850913]

36. Schoeppel SL, LaVigne ML, Martel MK, et al. Three-dimensional treatment planning of intracavitary gynecologic implants: Analysis of ten cases and implications for dose specification. Int J Radiat Oncol Biol Phys. 1994; 28:277-283. [PubMed: 8270452]

37. Ling CC, Schell MC, Working KR, et al. CT-assisted assessment of bladder and rectum dose in gynecological implants. Int J Radiat Oncol Biol Phys. 1987; 13:1577-1582. [PubMed: 3624031]

38. Measurements ICoRUa. ICRU report 38: Dose and volume specification for reporting intracavitary therapy in gynecology. Bethesda: International Commission on Radiation Units and Measurements; 1985.

39. Barillot I, Horiot JC, Maingon P, et al. Maximum and mean bladder dose defined from ultrasonography: Comparison with the ICRU reference in gynaecological brachytherapy. Radiother Oncol. 1994; 30:231-238. [PubMed: 8209007]

40. Kirisits C, Potter R, Lang S, et al. Dose and volume parameters for MRI-based treatment planning in intracavitary brachytherapy for cervical cancer. Int J Radiat Oncol Biol Phys. 2005; 62:901911. [PubMed: 15936576]

41. Potter R, Haie-Meder C, Van Limbergen E, et al. Recommendations from gynaecological (GYN) GEC ESTRO working group (II): Concepts and terms in 3D image-based treatment planning in cervix cancer brachytherapy-3D dose volume parameters and aspects of 3D image-based anatomy, radiation physics, radiobiology. Radiother Oncol. 2006; 78:67-77. [PubMed: 16403584]

42. Georg P, Dimopoulos J, Kirisits C, et al. The predictive value of dose volume parameters in MRI based cervical cancer brachytherapy for late adverse side effects in rectum, sigmoid and bladder. Int J Radiat Oncol Biol Phys. 2006; 66:S42. 
43. Viswanathan AN, Racine M, Cormack R. Final results of a prospective study of MR-based interstitial gynecologic brachytherapy. Brachytherapy. 2008; 7:148.

44. Viswanathan AN, Cormack R, Holloway CL, et al. Magnetic resonance-guided interstitial therapy for vaginal recurrence of endometrial cancer. Int J Radiat Oncol Biol Phys. 2006; 66:91-99. [PubMed: 16839709]

45. Peeters ST, Heemsbergen WD, van Putten WL, et al. Acute and late complications after radiotherapy for prostate cancer: Results of a multicenter randomized trial comparing 68 Gy to 78 Gy. Int J Radiat Oncol Biol Phys. 2005; 61:1019-1034. [PubMed: 15752881]

46. Karlsdottir A, Muren LP, Wentzel-Larsen T, et al. Late gastrointestinal morbidity after threedimensional conformal radiation therapy for prostate cancer fades with time in contrast to genitourinary morbidity. Int J Radiat Oncol Biol Phys. 2008; 70:1478-1486. [PubMed: 18060703]

47. Cahlon O, Zelefsky MJ, Shippy A, et al. Ultra-high dose ( 86.4 Gy) IMRT for localized prostate cancer: Toxicity and biochemical outcomes. Int J Radiat Oncol Biol Phys. 2008; 71:330-337. [PubMed: 18164858]

48. Schultheiss TE, Lee WR, Hunt MA, et al. Late GI and GU complications in the treatment of prostate cancer. Int J Radiat Oncol Biol Phys. 1997; 37:3-11. [PubMed: 9054871]

49. Eifel PJ, Jhingran A, Bodurka DC, et al. Correlation of smoking history and other patient characteristics with major complications of pelvic radiation therapy for cervical cancer. J Clin Oncol. 2002; 20:3651-3657. [PubMed: 12202666]

50. Chen GD, Lin LY, Wang PH, et al. Urinary tract dysfunction after radical hysterectomy for cervical cancer. Gynecol Oncol. 2002; 85:292-297. [PubMed: 11972390]

51. Axelsen SM, Bek KM, Petersen LK. Urodynamic and ultrasound characteristics of incontinence after radical hysterectomy. Neurourol Urodyn. 2007; 26:794-799. [PubMed: 17487872]

52. Green N, Treible D, Wallack H. Prostate cancer: Post-irradiation incontinence. J Urol. 1990; 144(2 Pt 1):307-309. [PubMed: 2115597]

53. Levine LA, Richie JP. Urological complications of cyclophosphamide. J Urol. 1989; 141:10631069. [PubMed: 2651710]

54. Eifel PJ, Winter K, Morris M, et al. Pelvic irradiation with concurrent chemotherapy versus pelvic and para-aortic irradiation for high-risk cervical cancer: An update of Radiation Therapy Oncology Group trial (RTOG) 90-01. J Clin Oncol. 2004; 22:872-880. [PubMed: 14990643]

55. Lindholt J, Hansen PT. Prostatic carcinoma: Complications of megavoltage radiation therapy. Br J Urol. 1986; 58:52-54. [PubMed: 3081075]

56. Vanuytsel L, Ang KK, Vandenbussche L, et al. Radiotherapy in multiple fractions per day for prostatic carcinoma: Late complications. Int J Radiat Oncol Biol Phys. 1986; 12:1589-1595. [PubMed: 3759584]

57. Horwich A, Dearnaley D, Huddart R, et al. A randomised trial of accelerated radiotherapy for localised invasive bladder cancer. Radiother Oncol. 2005; 75:34-43. [PubMed: 15878099] 


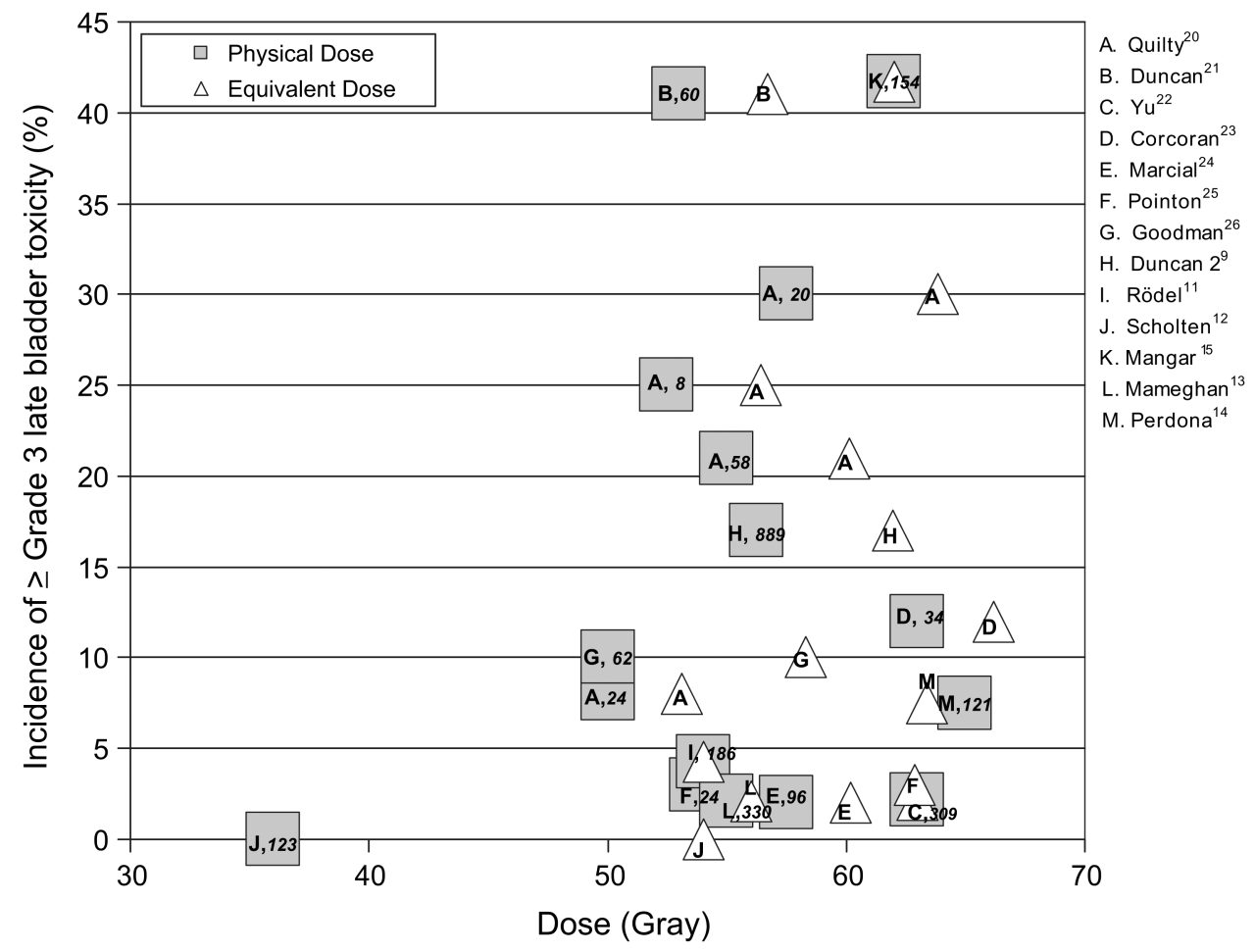

Fig. 1.

Incidence of Radiation Therapy Oncology Group Grade 3 or greater late bladder toxicity in relation to average dose (squares) or linear-quadratic model equivalent dose (triangles) in 2Gy fractions (assuming $a / \beta=6 \mathrm{~Gy}$ ) for studies treating whole bladder only (listed in Table 1 and reviewed by Marks, et al. [1]). Letter in each square denotes data source: publication specified in key as first author followed by superscript reference number. Note, Quilty and Duncan (20) had four dose groups. Number of patients italicized inside each square. No significant correlation was found between complication rate and either dose or equivalent dose. (Courtesy of E.D. Yorke.) 


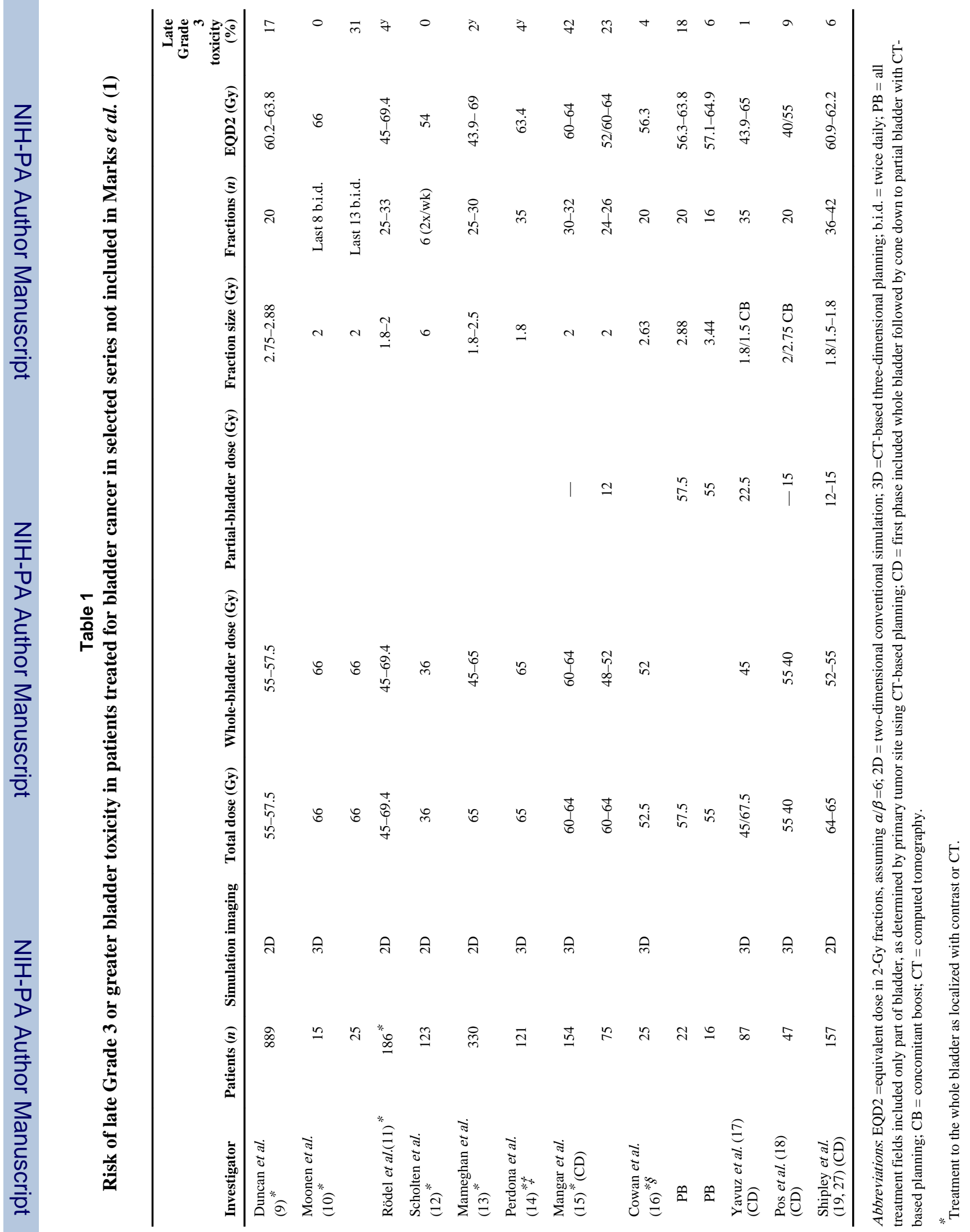

Int J Radiat Oncol Biol Phys. Author manuscript; available in PMC 2013 March 05. 
